\title{
PRODUCCION Y CONSUMO INDUSTRIAL DE LANA EN ESPAÑA (1849-1900) *
}

\author{
ANTONIO PAREJO BARRANCO
}

Universidad de Málaga

Las páginas que siguen pretenden participar, siquiera mínimamente, de la necesidad de ampliar nuestro conocimiento sobre la historia industrial española a otros sectores, al margen del siderúrgico y el textil algodonero, en la línea apuntada recientemente por Nadal ${ }^{1}$, Tortella ${ }^{2}$ o Berg ${ }^{3}$. Se trata, en este caso, de calcular el volumen de materia prima consumido por el subsector textil lanero en la segunda mitad del siglo xIx; una estimación más compleja que la que pueda llevarse a cabo en el caso del algodón - que no ofrece apenas dificultades, al tratarse de una fibra importada casi en su totalidad-, debido a que, como se sabe, a las cifras de entrada de lana del extranjero es necesario añadir el volumen aportado por la cabaña nacional, cuya participación no siempre resulta fácil de evaluar.

Pese a estos inconvenientes, hasta el momento disponemos al menos de tres trabajos que intentan establecer la dimensión de ambas magnitudes —producción y consumo- en la segunda parte del Ochocientos: me refiero al realizado hace algunos años por Sánchez-Albornoz ${ }^{4}$ y a los más inmediatos de Leandro Prados ${ }^{5}$ y Albert Carreras ${ }^{6}$. El cuadro 1 recoge los resultados aportados por los tres autores para los años 1860-65 y 1890-91; como quiera que la elaboración de los datos, las cifras facilitadas e incluso las conclusiones son distintas en todos los casos, he optado por resumir las distintas variables, analizándolas críticamente, para a continuación aportar una propuesta alternativa de estimación del consumo de lana realizado por las fábricas españolas de hilados $\mathrm{y}$ tejidos.

* El presente artículo resume un capítulo de mi libro, de próxima publicación, La In. dustria lanera española en la segunda mitad del siglo XIX. Deseo expresar aquí mi agradecimiento a los profesores Antonio M. Bernal, Albert Carreras, Jordi Nadal, Leandro Prados y Pedro Tedde, por la lectura y los comentarios realizados sobre el original.

'Nadal (1987).

2 Tortella (1981).

3 Berg (1987).

- Sánchez-Albornoz (1981).

"Prados (1983), (1988).

- Carreras (1983a). 


\section{CUADRO 1}

Producción y consumo de lana en España, 1860-65/1890-91. Estimaciones de Sáncbez-Albornoz (NSA), Leandro Prados (LPE) $y$ Albert Carreras ( $A C O$ )

(Equivalentes en lana lavada, en toneladas métricas)

1. PRODUCCION NACIONAL DE LANA LAVADA

\begin{tabular}{|c|c|c|c|}
\hline & $N S A$ & $L P E$ & $A C O$ \\
\hline $\begin{array}{lllllll}1860-65 & \ldots & \ldots & \ldots & \ldots & \ldots & \ldots \\
1890-91 & \ldots & \ldots & \ldots & \ldots & \ldots & \ldots\end{array}$ & $\begin{array}{r}18.711 \\
9.560\end{array}$ & $\begin{array}{l}19.099 \\
11.356\end{array}$ & $\begin{array}{r}16.777 \\
8.412\end{array}$ \\
\hline
\end{tabular}

2. IMPORTACION DE LANA LAVADA

\begin{tabular}{|c|c|c|c|}
\hline & $N S A$ & $L P E$ & $A C O$ \\
\hline $\begin{array}{lllllll}1860-65 & \ldots & \ldots & \ldots & \ldots & \ldots & \ldots \\
1890-91 & \ldots & \ldots & \ldots & \ldots & \ldots & \ldots\end{array}$ & $\begin{array}{l}4.658 \\
5.340\end{array}$ & $\begin{array}{l}1.972 \\
2.567\end{array}$ & $\begin{array}{l}1.021 \\
1.972\end{array}$ \\
\hline
\end{tabular}

3. IMPORTACION DE LANA LAVADA

\begin{tabular}{|c|c|c|c|}
\hline & $N S A$ & $L P E$ & $A C O$ \\
\hline $\begin{array}{lllllll}1860-65 & \ldots & \ldots & \ldots & \ldots & \ldots & \ldots \\
1890-91 & \ldots & \ldots & \ldots & \ldots & \ldots & \ldots\end{array}$ & $\begin{array}{r}88 \\
2.347\end{array}$ & $\begin{array}{r}121 \\
2.162\end{array}$ & $\begin{array}{l}149,6 \\
2.421\end{array}$ \\
\hline
\end{tabular}

4. CONSUMO APARENTE DE LANA

\begin{tabular}{|c|c|c|c|}
\hline & $N S A$ & $L P E$ & $A C O$ \\
\hline $\begin{array}{lllllll}1860-65 & \ldots & \ldots & \ldots & \ldots & \ldots & \ldots \\
1890-91 & \ldots & \ldots & \ldots & \ldots & \ldots & \ldots\end{array}$ & $\begin{array}{r}14.141 \\
6.567\end{array}$ & $\begin{array}{l}17.248 \\
10.951\end{array}$ & $\begin{array}{r}15.905 \\
8.861\end{array}$ \\
\hline
\end{tabular}

Fuentes: Sánchez-Albornoz (1981); Prados (1983); Carreras (1983 b).

\section{a) PRODUCCION NACIONAL Y CONSUMO DE LANA LAVADA}

En todos los cálculos disponibles, el volumen de producción nacional de lana disminuye considerablemente entre mediados y finales del siglo pasado, debido a que las estimaciones se realizan en base a los censos ganaderos de 1865 y 1891 (según el primero, la cabaña ovina ascendería'a 22.468 .969 ejemplares, frente a los sólo 13.359.473 que ofrece el segundo) ${ }^{7}$.

i GEHR (1978-79). 
Para evaluar el volumen de lana lavada a disposición de la industria, Sánchez-Albornoz establece un método de conversión que se basa en considerar un peso medio del vellón de 2,25 kgs. para los carneros, 1,25 kgs. para las ovejas y $0,52 \mathrm{kgs}$. para los corderos, calculando que en 1865 un 50 por 100 de la cabaña correspondería a ejemplares machos, un 37,5 por 100 a hembras y el 12,5 por 100 restante a crías, porcentajes que multiplicados por los coeficientes respectivos arrojarían un total de $37.422 \mathrm{tm}$. de lana sucia. A finales de siglo, la distribución de la cabaña había variado sensiblemente, al producirse un acusado descenso del número de carneros frente a las ovejas y las crías, lo que implicó que al descenso de lana disponible como consecuencia de la pérdida de cabezas entre una y otra fecha se sumara ahora la menor participación de los animales mejor dotados de materia prima: la lana en rama sólo ascendería entonces a $19.121 \mathrm{tm}$. En fin, el citado autor considera para ambas fechas una pérdida de peso del 50 por 100 en las operaciones de preparado y lavado.

Por su parte, Leandro Prados no distingue sexo ni edad en la cabaña, adoptando un peso algo más elevado del vellón $-2 \mathrm{kgs} /$ ejemplar-, pero una mayor pérdida en el lavaje - merma de $0,575 \mathrm{gr} / \mathrm{kg}$.-, lo que a la postre arroja el mismo rendimiento de lana por cabeza para 1860.65 que en el caso de Sánchez-Albornoz: $0,85 \mathrm{kgs} .{ }^{8}$, aunque sus estimaciones del volumen de 1890-91 son algo más elevadas al no tener en cuenta la distinta distribución por sexos de la cabaña.

En cuanto a Albert Carreras, utiliza las estimaciones de Sánchez-Albornoz, si bien modifica las de $1860-65$ al tomar como datos del censo el mismo volumen que Leandro Prados.

Los resultados, una vez reducidos a lana lavada, muestran un acusado descenso - prácticamente a la mitad- del volumen de lana producido. Esta fortísima reducción es escasamente discutida por Sánchez-Albornoz, pero mucho más por Carreras y Prados: éste acepta las cifras oficiales del censo de 1865 , pero presenta sus reservas respecto al de $1891^{9}$, mientras Carreras expresa sus dudas especialmente sobre el censo de $1865^{10}$, lo que más adelante le llevará a ofrecer un método alternativo para evaluar la producción nacional de hilados de lana.

En lo que respecta a la exportación de fibra, la fuente empleada es la misma en los tres casos - las ECEX-, si bien la acusada diferencia entre los datos que aportan Sánchez-Albornoz, por un lado, y Prados y Carreras, por otro, se debe a que el primero no reconvierte la lana sucia en lavada; mientras que

- Leandro Prados acepta un rendimiento del 42,5 por 100 por cabeza. Prados (1983), p. 469.

Ibid., p. 457.

10 Carreras (1983 a), II, p. 538. 
entre estos dos últimos la disimilitud obedece a la utilización de medias trienales centradas, en el caso de Prados, y a los distintos porcentajes de conversión empleados por ambos investigadores. Por lo que se refiere a las cifras de importación, aunque los tres autores emplean para sus estimaciones los datos facilitados por las ECEX, desconozco qué tipo de método de conversión han empleado Sánchez-Albornoz y Prados de la Escosura para reducir a lana lavada la peinada y la cardada - doy por supuesto que mantienen los mismos porcentajes para convertir la lana sucia en lavada-, aunque el hecho de que Sánchez-Albornoz presente sus cifras como «lana en rama» inclina a pensar que no ha desagregado los volúmenes correspondientes a uno y otro tipo de fibra. De otro lado, Prados sigue aportando medias trienales centradas, y Carreras ofrece las cifras en lana peinada, que yo he transformado en lavada para poder homogeneizar los resultados, de acuerdo con el porcentaje que él mismo aporta: 10 por 100 de merma en la operación de peinado o cardado. Por último, ninguno considera las importaciones de estambre hilado -en blanco o teñido-, que también deberían añadirse al total de fibra consumida.

En fin, pese a que en los tres casos se incluyen datos sobre el consumo de lana, los de Sánchez-Albornoz deben desecharse, ya que al apartado 1 (lana lavada) añade y deduce otros (apartados 2 y 3 , respectivamente) que no distinguen entre lana sucia y lavada, con claro predominio de aquélla en las cifras de exportación. Mayor homogeneidad presentan las estimaciones de Prados y Carreras, si bien, en última instancia, ni la columna de importación ni la de exportación modifican sensiblemente la tendencia apuntada en la producción nacional de lana lavada. De alguna manera, esta importante flexión del consumo entre una y otra fecha tendería a confirmar las opiniones de Sánchez-Albornoz, quien relaciona este descenso con la agresividad mostrada por el subsector fabril más avanzado -el textil algodonero-, que arrebataría a los restantes - tradicionales, entre los que incluye la lana - una cuota de mercado que hasta entonces habian satisfecho de forma mayoritaria.

Es ahora Carreras quien apunta la incongruencia de este descenso -que, evidentemente, contrasta con el aumento de las instalaciones fabriles lanerasy quien expresa sus reservas ante el teórico papel sustitutivo de los géneros de lana que pudo suponer el algodón, terminando por desechar las posibilidacles estimativas derivadas de la elaboración de los datos censales, tal como la lleva a cabo Sánchez-Albornoz".

"Ibid., p. 539. 
a') Las posibilidades de una estimación alternativa de producción y consumo industrial de lana

Como el apartado anterior acaba de poner de manifiesto, todas aquellas apreciaciones de producción nacional de lana durante la segunda mitad del xIX basadas en la elaboración de las cifras facilitadas por los censos de 1865 y 1891 , por muy precisas y ajustadas que se pretendan, presentarán un perfil inequívocamente descendente. La fiabilidad de ambos recuentos se muestra, así, como la primera de las dificultades a superar para establecer una estimación ponderada de la producción de lana, aunque no como la única: los niveles de utilización industrial de la lana procedente de la cabaña nacional -que en ningún caso podrían ser del cien por cien-y los coeficientes de rendimiento aplicables a la fibra animal son dos extremos que, asimismo, deben valorarse adecuadamente a la hora de aportar una evaluación alternativa. Por último, el coeficiente de conversión a emplear para pasar de uno a otro estado de elaboración de la materia textil -lana sucia, lavada y peinada - adquiere especial significación en las columnas de importación y exportación de fibra.

\section{a'a) La producción nacional de lana lavada en la segunda mitad del siglo XIX}

Pese a las reservas expresadas por Albert Carreras, el censo de 1865 -primero de los realizados en el siglo xIX- parece el más fiable de todos los que disponemos para el período estudiado. Esta es, al menos, la opinión que últimamente mantienen, entre otros, Santiago Zapata ${ }^{12}$ y Domingo Gallego ${ }^{13}$, quienes lo consideran como el más aproximado al volumen real de la cabaña, así como el único cuyos resultados son homogeneizables con los que ofrecen los más exactos llevados a cabo en 1929 y $1933^{14}$. Por el contrario, prácticamente todos los autores que en fechas recientes se han ocupado de la crisis pecuaria finisecular son muy críticos con el «Avance» de $1891^{15}$. Así, Jiménez Blanco expresa cómo «la cuantía [se refiere al descenso de la cabaña entre una y otra fecha] es, sin embargo, demasiado elevada para no dudar de la fiabilidad de las cifras, por cuanto una depresión de esta magnitud únicamente resultaría creíble en el caso de una catástrofe ganadera, que no habría pasado desapercibida a los contemporáneos, y de la que no tenemos noticia [...] los indicios disponibles llevan a pensar que el mal llamado censo de 1891 incurre

12 Zapata (1986).

${ }^{13}$ Gallego (1986).

14 Los censos de 1929 y 1933 arrojaban un total de 19.369 .443 y 19.093 .319 cabezas lanares, respectivamente. Gallego (1986), II, p. 595.

is' Junta Consultiva Agronómica (1892). 
en una notable infravaloración...» ${ }^{16}$. Por su parte, Domingo Gallego se muestra todavía más categórico: «la conclusión principal es que los censos de 1865 y 1891 no son comparables: o fueron elaborados con criterios distintos o los niveles de ocultación son muy dispares, siendo estos factores los responsables de la disminución de los datos censales, y no la evolución real de la ganadería en ese período, de la que por ahora ignoramos casi todo" ${ }^{17}$.

Desgraciadamente, para fechas intermedias sólo contamos con estimaciones, en casi todos los casos, tan imperfectas como el "Avance» de 1891 o, cuando menos, realizadas con métodos de elaboración que desconocemos. Así, en 1879, la Sociedad Económica Matritense, en un informe recogido por la CEA, indicaba que, según datos de la Dirección General de Contribuciones, la cabaña lanar ascendía a 20.339.949 ejemplares ${ }^{18}$, volumen congruente tanto con las cifras de 1865 como con el sostenido descenso que sabemos se venía produciendo, al menos, desde mediados del Ochocientos. Ese mismo año, sin embargo, la Estadística Administrativa de la Riqueza Pecuaria sólo declaraba la existencia de algo más de 14 millones de cabezas, mientras que, también por las mismas fechas, para el secretario de la Asociación General de Ganaderos, Miguel López Martínez, «se puede calcular que el número de cabezas asciende actualmente a veintidós millones» ${ }^{19}$.

En los años ochenta, todas las estimaciones que he podido localizar - aportadas por industriales, ganaderos o políticos participantes en las discusiones sobre la reforma de aranceles y la crisis pecuaria-, quizá por basarse en los datos ofrecidos por López Martínez, sitúan el volumen de la cabaña entre los 20 y 22 millones de cabezas ${ }^{20}$, y, lo que es más significativo, las observaciones que acompañan las cifras, aun admitiendo la crisis del sector, en ningún caso denotan el teórico derrumbamiento ovino que en esa década debía haberse producido, según el «Avance» de 1891. En fin, para la Junta Consultiva Agronómica, en 1888 la cabaña lanar española ascendería a 16.469 .303 ejemplares ${ }^{21}$.

En cuanto a los censos disponibles para fechas inmediatamente posteriores - ya a comienzos de nuestro siglo-, los recientes trabajos de Zapata, Gallego y Jiménez Blanco, ya citados, han demostrado que, como en el recuento de 1891, también carecen de la fiabilidad suficiente como para poder enlazar sus datos —en torno a los 13,5 millones de cabezas en 1905-1907_ con los de $1865^{22}$.

En cualquier caso, y pese a las precariedades estadísticas ya apuntadas, el

16 Jiménez Blanco (1986), pp. 20-21.

17 Gallego (1986), II, p. 588.

18 CEA, III (1881), p. 46.

19 López Martínez (1879), p. 68.

20 ILE, 15-V-1881; GI (1881), p. 133; GA, 16-I-1890.

21 RA, VI (1890), p. 78.

22 Gallego (1986), II, pp. 577, 589 y 591. 
descenso de la cabaña lanera española en la segunda mitad del siglo xIX parece fuera de toda discusión: sin embargo, al margen de las causas que condicionaron este comportamiento -incremento de la superficie agrícola, pérdida de competitividad de la lana nacional en los mercados internacionales, contracción de la demanda interior, etc.-, esta caída se produjo en unos términos inferiores a los presentados por los censos y recuentos oficiales. En concreto, tanto el análisis crítico del de 1891 como la opinión de los contemporáneos del fenómeno, y las recientes conclusiones de algunos miembros del GEHR, permiten aventurar que el descenso no arrancó en 1865, sino al menos una década antes ${ }^{23}$; y que fue moderado aproximadamente hasta 1880 - son aceptables los 20,3 millones para 1879 - y un tanto más acusado a partir de ese año y hasta $1895^{24}$, en que se iniciaria una sostenida recuperación, reafirmada a par. tir de $1908^{25}$. Puestos a dar cifras, serían plausibles unos 24 millones de cabezas hacia 1850 , los ya admitidos 22,4 de 1865 y 20,3 de 1879 , y algo más de 16 millones para $1890-95$.

Partimos ya de unos volúmenes estimativos distintos a los que conforman la base de los cálculos efectuados por Sánchez-Albornoz, Prados y Carreras para 1891, que, evidentemente, deben revisarse al alza; pero, además, hay al menos otras dos cuestiones a replantear antes de traducir esas estimaciones en cifras de consumo de lana realizado por las fábricas textiles españolas: la consideración «industrial» de la fibra que, teóricamente, estaba en condiciones de aportar la cabaña nacional y los métodos de conversión utilizados para transformar la lana procedente del vellón en lana hilable. En lo que se refiere al primer aspecto, ha sido Carreras el único que lo ha sometido a discusión ${ }^{26}$, aunque sin llegar a establecer ningún porcentaje de utilización industrial de la lana española. Por mi parte, estoy de acuerdo con sus apreciaciones, aunque, más allá, me atrevo a dar una cifra máxima de empleo industrial de la lana procedente de la cabaña nacional.

Para ello resulta necesario ocuparse de la composición racial de la cabaña ovina española en el período tratado, ya que no todas las razas ofrecían las mismas posibilidades de aprovechamiento industrial, e incluso algunas apenas permitían su elaboración textil. En España, estas lanas bastas u ordinarias procedian de la llamada raza «churra", que junto con la merina y entrefina conformaban el grueso de la cabaña nacional.

En efecto, los especialistas tienden a considerar la existencia secular en nuestro país de tres tipos de razas ovinas: la merina, la rasa o entrefina, y la churra o riberiega. La primera era, desde luego, la productora de lana por ex-

${ }^{23}$ Zapata (1986), I, p. 623

24 Ibid., p. 624 .

25 Jiménez Blanco (1984), I, p. 259.

${ }^{26}$ Carreras (1983 a), II, p. 538. 
celencia: asentada sobre todo en Extremadura, Castilla y Andalucía, el merino ofrecía una fibra extremadamente fina -entre 14 y 24 micras, según los tipos- y rizada, lo que incrementaba su valor como materia textil; con un alto grado de flexibilidad, elasticidad y suavidad, aunque al tratarse de una fibra corta - de 4 a $6,5 \mathrm{cms}$. de longitud- no presentaba cualidades estambreras, quedando restringido su uso como hilo de carda. Asimismo, su vellón se componía en un porcentaje elevado de suarda o grasa, lo que afectaba al rendimiento en el lavaje.

Las lanas entrefinas suponían el cruce de ejemplares merinos y churros. La raza era, quizá por ello, la más extendida, con una serie de subrazas clasificadas de acuerdo con su localización geográfica (manchega, castellana, aragonesa, segoviana, etc.). De menor finura que la merina -entre 25 y $35 \mathrm{mi}$ cras-, la fibra era, sin embargo, más larga $-7 \mathrm{cms}$. - lo que ocasionalmente permitió, en la segunda mitad del Ochocientos, su utilización como fibra estambrera ${ }^{n}$.

En fin, las churras y lachas abundaban por numerosas zonas de la Península (las principales variedades eran la manchega, castellana, riojana y montánchez), pero su fibra, extremadamente basta - más de 40 micras de grosor- la convertía en lana no textil: en el período que nos ocupa, sólo la manchega se empleaba para la confección de paños de baja calidad en las fábricas de Alcoy y Enguera, mientras que el consumo del resto quedaba limitado a la elaboración de alfombras, tapices y sombrerería, así como a la colchonería, para lo que era una lana especialmente apreciada ${ }^{28}$.

Más difícil resulta establecer el porcentaje de cabezas que, en la época estudiada, correspondería a cada una de las razas, ya que ni el censo de 1865 ni los recuentos posteriores especifican nada al respecto, y sólo tras la guerra civil he podido localizar estimaciones de este tipo. Cabe pensar, no obstante, que la distribución racial no se modificaría sustancialmente entre finales del xIx y mediados del $\mathrm{xx}$, por lo que pueden adoptarse los siguientes porcentajes: 24,4 por 100 para la raza merina, 49,6 por 100 para la rasa y 26 por 100 para la churra (el cuadro 2 ofrece las cifras desagregadas por subrazas) ${ }^{29}$; ello significaría que, del total de la cabaña nacional, al menos un 20 por 100 -evaluando en un 6 por 100 la lana procedente de la raza churra que se empleaba en la fabricación de paños bastos- debe considerarse como no textil y, por tanto, deducible del volumen de partida tanto en 1865 como en 1891.

${ }^{37}$ Aragó (1893), p. 20.

${ }^{26}$ López Martínez (1879), p. 9; Aragó (1893), p. 17.

${ }^{29}$ El único que he localizado que presenta una distribución de este tipo es Jerónimo Martón, pero al no distinguir entre lana fina y entrefina, ni en ocasiones tampoco entre lana fina y basta, hace prácticamente imposible la elaboración de los datos que aporta. Martón (1908), p. 44. 


\section{CUADRO 2}

Cabaña ovina nacional. Distribución racial en porcentajes (1), peso del vellón en kilogramos (2) y rendimiento en el lavado en porcentajes (3)

(Estimaciones aproximadas para la segunda mitad del xIX)

\begin{tabular}{|c|c|c|c|}
\hline Razas y subrazas & (1) & $(2)$ & (3) \\
\hline 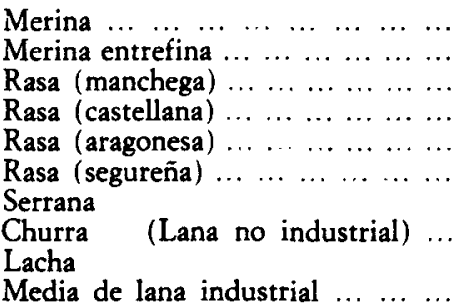 & $\begin{array}{r}17,1 \\
7,3 \\
16,2 \\
17,7 \\
11,5 \\
3,7 \\
26,09(6,0) \\
80\end{array}$ & $\begin{array}{l}2,1 \\
2,5 \\
2 \\
1,8 \\
1,8 \\
1,8\end{array}$ & $\begin{array}{l}40 \\
40 \\
35 \\
36 \\
34 \\
40\end{array}$ \\
\hline
\end{tabular}

FuENTES: Aragó (1893); Arán (1958). Elaboración propia.

La segunda matización a las estimaciones de Prados, Carreras y SánchezAlbornoz se refiere al peso del vellón y a la pérdida sufrida por éste en las operaciones de limpieza y lavado a que debía someterse la fibra. Como apunté más arriba, Sánchez-Albornoz y Carreras consideraban una media de 1,87 kgs. por cabeza, y Prados, de $2 \mathrm{kgs}$. Se trata de cifras muy parecidas, que coinciden con las valoraciones realizadas por los especialistas de la época ${ }^{30} \mathrm{y}$, también, con la que yo he establecido $-2 \mathrm{kgs}$.- luego de ponderar la aportación de las diferentes razas "textiles», ya que, como se desprende del cuadro 2 , cada tipo de raza ofrecía un distinto peso del vellón.

Por lo que respecta al rendimiento de la fibra (columna 3 del cuadro 2), pienso que los tres autores son demasiado optimistas: ciertamente, el 42,5 por 100 que apunta Prados es un porcentaje que repiten la mayoría de los tratados técnicos publicados entonces, pero que se refiere más al conjunto de lana nacional que a aquella de uso industrial, que solía tener una pérdida más elevada en el lavaje - recuérdese el alto porcentaje de suarda de la merina ${ }^{31}$ y no rendir nunca más allá del 40 por 100 . De nuevo, el cuadro 2 permite establecer una media adecuada, que puede situarse en el 39,1 por 100.

${ }^{30}$ Ronquillo (1857) recoge una memoria en la que señalaban 2 kgs. por cabeza; $2,5 \mathrm{kgs/}$ ejemplar es la media que expresa López Martínez (1879); 1,88, Santos Arán (1958), y 2,5 lo que consideraba la Comisión para el Estudio de la Crisis Agrícola y Pecuaria (GA, 16 I-1890). Sobre el problema del coeficiente a emplear, véase Zapata (1986), II, pp. 676-686.

${ }_{31}$ Según un examen de lana en bruto recogido por Martón (1908), p. 23, 100 kgs. desecados a $100^{\circ}$ arrojaron un 32,7 por 100 de suarda. 
Con las rectificaciones anteriores -al número de cabezas, al peso del vellón y al rendimiento-, la producción nacional de lana lavada a disposición de la industria quedaría fijada en un máximo de $14.002 \mathrm{tm}$. para 1865 y de $11.568 \mathrm{tm}$. para 1891. ¿Son aceptables estos datos? Pese a que muestran un descenso mucho más suave de la producción interior, por el momento deben tomarse simplemente como una estimación más, como el nivel más elevado de fibra que en ambos momentos podía aprovechar la industria nacional. Sólo el análisis de las dos variables siguientes -exportación e importación de lanapermitirá establecer la evolución del consumo realizado por las fábricas españolas y constatar si es congruente con el sensible incremento del utillaje que, como sabemos, se produjo en el subsector lanero en este período ${ }^{32}$.

\section{a'b) La exportación de lana en la segunda mitad del siglo XIX}

Evidentemente, se trata de la variable que modifica a la baja el volumen de fibra a disposición de la industria textil nacional. Los datos facilitados por las ECEX se han reducido a lana lavada, utilizando el porcentaje de conversión ya apuntado - 39,1 por 100 - para poder homogeneizarlos con las estimacior.es de la producción de lana reseñadas más arriba. Son los que conforman la serie anual que ofrece la columna 1 del cuadro 3 para el período comprendido entre 1849 y 1900 .

\section{CUADRO 3}

España. Exportaciones e importaciones de lana, 1849-1900. Exportaciones (1), importaciones (2), exportaciones/importaciones (3) (Equivalentes en lana lavada, en toneladas métricas)

\begin{tabular}{|c|c|c|c|}
\hline & (1) & (2) & (3) \\
\hline $\begin{array}{llllllll}1849 & \ldots & \ldots & \ldots & \ldots & \ldots & \ldots & \ldots \\
1850 & \ldots & \ldots & \ldots & \ldots & \ldots & \ldots & \ldots \\
1851 & \ldots & \ldots & \ldots & \ldots & \ldots & \ldots & \ldots \\
1852 & \ldots & \ldots & \ldots & \ldots & \ldots & \ldots & \ldots \\
1853 & \ldots & \ldots & \ldots & \ldots & \ldots & \ldots & \ldots \\
1854 & \ldots & \ldots & \ldots & \ldots & \ldots & \ldots & \ldots \\
1855 & \ldots & \ldots & \ldots & \ldots & \ldots & \ldots & \ldots \\
1856 & \ldots & \ldots & \ldots & \ldots & \ldots & \ldots & \ldots \\
1857 & \ldots & \ldots & \ldots & \ldots & \ldots & \ldots & \ldots \\
1858 & \ldots & \ldots & \ldots & \ldots & \ldots & \ldots & \ldots \\
1859 & \ldots & \ldots & \ldots & \ldots & \ldots & \ldots & \ldots\end{array}$ & $\begin{array}{l}2.452,8 \\
3.788,4 \\
2.973,1 \\
3.350,2 \\
2.042,9 \\
1.270,8 \\
2.584,6 \\
2.214,3 \\
2.603,9 \\
1.148,1 \\
1.502,3\end{array}$ & $\begin{array}{l}35,3 \\
57,8 \\
27,8 \\
22,1 \\
24,7 \\
22,6 \\
36,1 \\
49,4 \\
48,5 \\
57,2 \\
76,1\end{array}$ & $\begin{array}{r}69,5 \\
65,5 \\
106,9 \\
151,6 \\
82,7 \\
56,2 \\
71,6 \\
44,8 \\
53,7 \\
20,1 \\
19,7\end{array}$ \\
\hline
\end{tabular}

"Nadal y Maluquer (1985); Nadal (1987); Parejo (en prensa). 


\section{CUADRO 3 (Continuación)}

España. Exportaciones e importaciones de lana, 1849-1900. Exportaciones (1), importaciones (2), exportaciones/importaciones (3) (Equivalentes en lana lavada, en toneladas métricas)

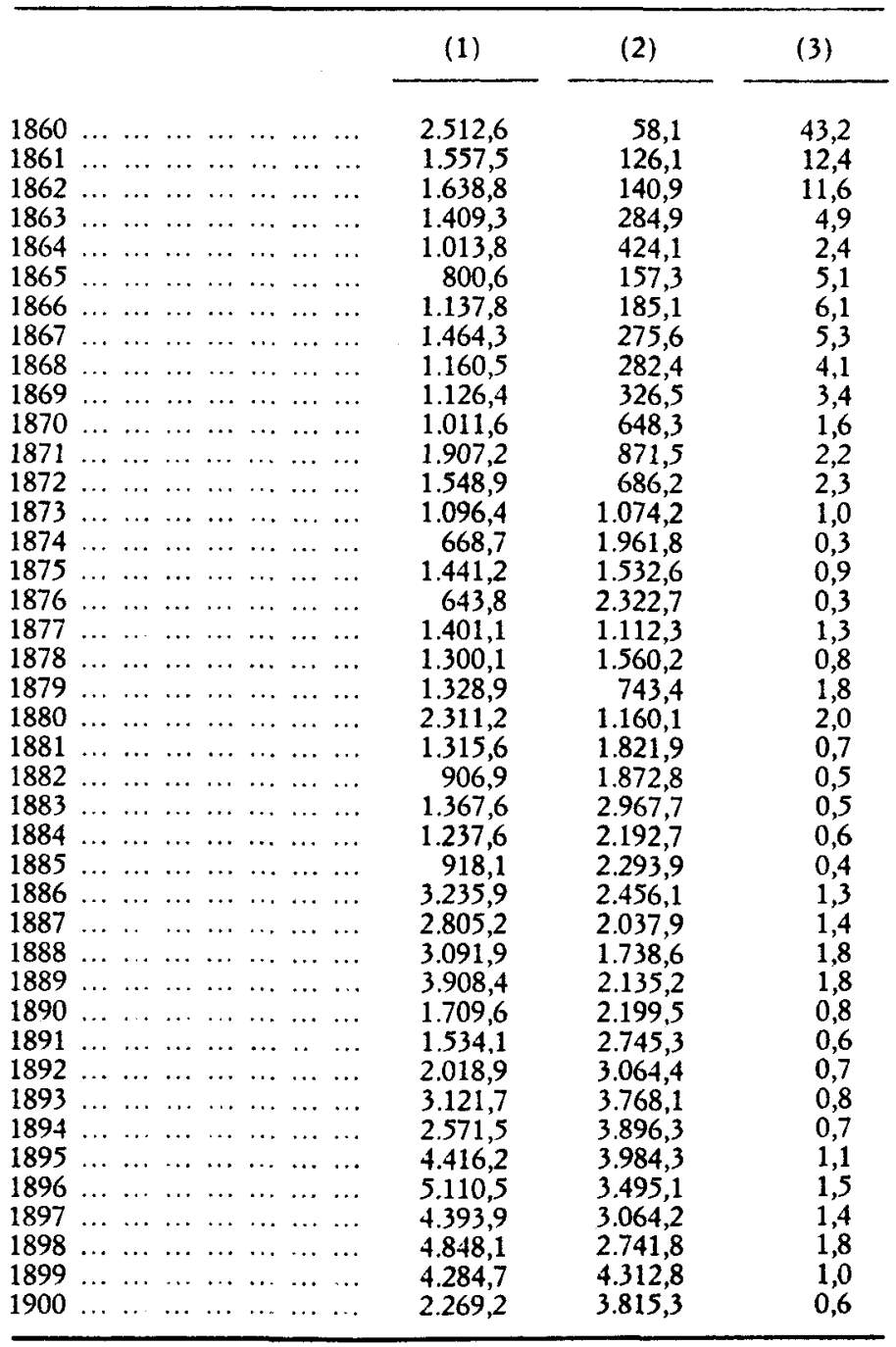

FuENTE: ECEX. Elaboración propia. 
Como es sabido, la tradicional dedicación exportadora de las lanas castellanas durante el Antiguo Régimen comenzó a quebrarse a finales del siglo xvill. Gracias, sobre todo, a los trabajos de García Sanz y Llopis Agelán ${ }^{33}$, conocemos suficientemente el proceso de desplazamiento irreversible que a partir de entonces sufrió la fibra española en el mercado europeo, y especialmente en el inglés. Según expresa el primero, el incremento de la demanda británica, provocado por la expansión del nuevo sector fabril, generó, de forma paradójica, una crisis en los niveles de exportación, que se agudizaría a partir de los años veinte: de un lado, las posibilidades ofrecidas por el mercado inglés aceleraton la aclimatación del merino español en otros países europeos, que pronto consiguieron resultados muy positivos tanto en la producción como en la calidad de la fibra ${ }^{34}$; de otro, y paralelamente, en España, las perspectivas de obtención de rápidos beneficios, ante el alza constante de los precios de la lana en el mercado europeo, determinaron un creciente deterioro de la calidad de la lana exportada, de forma que era progresivamente desdeñada por los consumidores británicos: la comparación de las cifras entre 1800 y 1827 deja poco lugar a discusión, ya que mientras en el primer año citado Inglaterra recibió 278,3 miles de arrobas, por sólo 15,0 procedentes de Alemania, en el segundo se invirtieron los términos, con 155,2 para España y 785,9 para las lanas sajonas ${ }^{35}$.

En términos globales, y ya reducidos a las unidades que vengo manejando, España exportó entre 1749 y 1768 una media anual de 4.628,1 tm. de lana lavada, 4.927,2 tm. en 1792, y sólo $1.530,3 \mathrm{tm}$. (media/año) en el quinquenio 1826-30. A partir de ese año $\rightarrow$ y se trata de datos que pueden enlazarse con la serie anual que ofrece el cuadro 4- se produjo una tímida recuperación $-2.592,9 \mathrm{tm}$. en 1835-, que se mantuvo al menos hasta los primeros años cincuenta - 3.261,5 tm. de lana lavada exportada entre 1849 y 1852 -, pareja a la que estaba teniendo lugar en el volumen y composición de la cabaña nacional, en la que el merino volvía a ganar posiciones con respecto a la lana entrefina $y$ ordinaria ${ }^{36}$.

Sin embargo, a partir de entonces y hasta 1885 , el descenso fue prácticamente ininterrumpido, y, además, en esta ocasión no se trató, o al menos no exclusivamente - tal como había sucedido a comienzos de siglo con la lana sajona-, de la competencia realizada por otras zonas productoras. Desde media-

${ }^{33}$ García Sanz (1978); Llopis (1982).

${ }^{34}$ García Sanz (1978), pp. 298-300. Sobre la exportación de ovejas merinas a otros paises europeos, véanse López Martínez (1879), pp. 14-15; Laguna (1986), pp. 183 y ss.; B. A. Zapata (1820); Gaminde (1827).

35 Garcia Sanz (1978), p. 304.

${ }^{36}$ Los datos de 1749-1768 están tomados de Llopis (1982), p. 33. Los de 1792 a 1835 , de Carreras ( 1983 a), II, p. 552 . La recuperación del merino ha sido señalada, entre otros, por García Sanz (1978), p. 307. La raza pasó de contar con 3,14 millones de ejemplares en 1832 a 4,36 en 1865 . 
dos del Ochocientos, el nuevo agravamiento de la situación de la lana española en el mercado internacional fue debido a la entrada en los circuitos de comercialización de las llamadas lanas «coloniales», procedentes de Sudamérica, Estados Unidos y Australia, que arrastraron a la baja los precios de la materia textil - y, por supuesto, los de la fibra exportada desde nuestro país-, y también a la progresiva sustitución del hilo de carda por un nuevo tipo de fibra: la lana larga o estambrera, a la que ya se hizo referencia al tratar de la especialización vallesana y sobre la que volveré más adelante, cuando analice su incidencia sobre el mercado español.

Para nuestros ganaderos, la cuestión ya no radicaba simplemente en mejorar la calidad de la fibra o elevar sus niveles de producción - lo que hubiera supuesto un mal menor, de lograrse hilo de primera calidad-, sino de llevar a cabo toda una adecuación radical de la cabaña a las nuevas condiciones de la demanda: algo fuera del alcance del ganadero español, que se veía incapaz de dotar a sus ejemplares de los mínimos y «solícitos cuidados que en el extranjero se les prodigan para la obtención de la cualidad más apetecida hoy que consiste en igualar la hebra y darle carácter estambrero... ${ }^{37}$. Todavía más, incluso la equitativa distribución porcentual de las exportaciones de lana en sucio y lavada se quebró definitivamente, a favor de la primera, a partir de 1863 , lo que contribuyó a mantener el fraude -mezclando lanas de diversas calidades- y, con él, la baja consideración de nuestras lanas en los mercados internacionales ${ }^{38}$. De tal forma, la doble amenaza que para la producción nacional representaba la baratura del hilo de carda ultramarino y la imposibilidad de conseguir de nuestros ejemplares hilo estambrero estuvo presente a lo largo de todo el período estudiado, en que apenas se modificó el papel de la fibra española en el mercado exterior, definiendo una situación irresoluble, al menos a corto plazo, para los productores nacionales ${ }^{39}$.

Sólo a partir de 1885 , España logró recuperar una cierta posición en el mercado europeo - 2.432,8,3.144,9 y 4.795,1 tm. de lana lavada exportadas para los quinquenios $1886-90,1891-95$ y 1896-1900, respectivamente-, aunque no precisamente debido a una mejora en la calidad de la fibra: en los últimos años del XIX, la lana basta comenzó a ser demandada por la industria británica, ante el crecimiento de un nuevo subsector, el de tejidos de lana regenerada o de baja calidad, mientras que coyunturales derrumbamientos de la producción ganadera australiana -como el provocado por la epidemia de $1894^{40}$ - y la depreciación finisecular de la peseta terminan por explicar esta nueva orientación alcista de las exportaciones de lana, que, en consonancia con

si RA, VI (1890), p. 185. Véase, también, GA, 16-I-1890.

38 Zapata (1986), p. 688.

$39 \mathrm{GA}, 15-1-1877$, pp. $17 \cdot 18$.

4 EEF, 24-II-1906, p. 115. 
el incremento de la demanda, se acompañó de una sensible recuperación de] precio de la fibra en el mercado internacional ${ }^{41}$.

En ningún caso, sin embargo, las exportaciones laneras españolas llegaron a representar un porcentaje significativo en el total nacional de ventas realizadas al exterior: un máximo de 5,1 por 100, en el quinquenio $1850-54$, y una media nanca superior al 1,8 por 100 , entre 1860 y 1885 ; mientras que, de alguna manera, el ya apuntado crecimiento finisecular fue absorbido por la diversificación de exportaciones que se produjo en esas fechas, lo que determinó que los porcentajes fuesen sólo del 1,7,1,2 y 1,7 por 100 para los quinquenios $1885-89,1890-94$ y $1895-99$, respectivamente ${ }^{42}$.

\section{a'c) La importación de lana en la segunda mitad del siglo XIX}

La columna 2 del cuadro 3 presenta la serie anual de importación de lana entre 1849 y 1900 , una vez reducida a equivalentes en lana lavada. Para convertir la no muy elevada materia textil «sucia» importada en fibra lavada he utilizado el porcentaje ya expresado $-39,1$ por 100 de rendimiento-, mientras que considero una merma del 30,8 por 100 - superior a la que apunta Carreras ${ }^{43}$ - en aquella lana estambrera que se importa una vez peinada, y he añadido el estambre hilado, que comienza a aparecer en las ECEX a partir de 1870 , y que ninguno de los tres autores citados en el cuadro 1 incluye en sus cálculos. Este doble factor explica que la serie que aporto presente, en todos los años, volúmenes superiores a los que ofrecen las estimaciones de producción y consumo de lana de que disponemos hasta el momento. Asimismo, al tratarse de datos anuales, permite un acercamiento mucho más preciso a la evolución de las compras de lana realizadas en el exterior en la segunda mitad del Ochocientos.

En el cuadro citado se observan claramente unos primeros años caracterizados por unos niveles de importación muy bajos - prácticamente insignificantes, con una media de $42,9 \mathrm{tm}$. entre 1849 y $1860-$, que inician un crecimien-

"Ibid. Sobre la depreciación de la peseta y su influencia en los niveles de exportación, Tortella (1981), pp. 93 y ss.

42 Prados (1982), p. 41.

${ }^{43}$ Los coeficientes de reducción que adopta Carreras se basan en las cifras of recidas por las valoraciones arancelarias, $y$ son las siguientes: lana bruta $=0,4$; lana lavada $=0,9$; lana peinada $=1$. Carreras $(1983$ a), II, p. 534 . La pérdida que yo considero $(30,8$ por 100$)$ se basa fundamentalmente en dos fuentes: 1) En la CEA se establecía una equivalencia de $1 \mathrm{~kg}$. de lana lavada para $2 \mathrm{kgs}$. en bruto, y de $1 \mathrm{~kg}$. de lana peinada para $4 \mathrm{kgs}$. en bruto (CEA, III, p. 106). 2) En 1883, la casa estambrera catalana «Cuadra, Feliú y Cía.» estableció los siguientes rendimientos porcentuales medios sobre lana lavada: desperdicio o pelusa separada para las fibras, 24,7 por 100; borra, 6,1 por 100; lana peinada con aceite, 69,2 por 100 (EP, 1-VI-1883, pp. 196-198). 
to moderado en los años sesenta $-226,6$ y $343,5 \mathrm{tm}$. para los quinquenios 1861-65 y 1866-70, respectivamente - y algo más acusado a partir de 1873-74, años en que las importaciones comienzan a superar el volumen de lana exportada (columna 3 del cuadro 3 ). Salvo hundimientos coyunturales -1877 , 1879-, el crecimiento es sostenido en el último tercio del siglo, acentuándose todavía más en la década finisecular, hasta llegar a doblar y triplicar el volumen de importación con respecto a los años inmediatamente anteriores: así, se pasa de $1.225,2 \mathrm{tm}$. de lana lavada de media quinquenal importada en $1871-75$, a $2.049,7 \mathrm{tm}$. en $1881-85$ y a $3.491,6 \mathrm{tm}$. en $1891-95$.

Si bien el hecho de que la industria lanera nacional disparase su consumo de fibra extranjera en las últimas décadas del Ochocientos puede estar relacionado con un aumento de la producción, lo cierto es que este comportamiento alcista también traslada el problema a dos cuestiones de importancia: la especialización en determinados tipos de tejidos, que exigian una clase de fibra que los fabricantes no podían conseguir en el interior, y la existencia de una política comercial lo suficientemente favorable a sus intereses como para rentabilizar la importación de la materia textil. La conjunción de ambos factores, junto con las limitaciones de la cabaña nacional, explican este considerable incremento de las compras en el exterior, aunque se trata de un fenómeno que no puede desligarse de las profundas transformaciones que al mismo tiempo estaban teniendo lugar en el subsector - la innovación tecnológica, los cambios en la estructura productiva y la propia especialización-, y que, además, se produjo en un período de expansión - y no de crisis- del textil lanero español ${ }^{4}$.

Por otra parte, el desarrollo de las importaciones originó un largo y nunca resuelto conflicto - al menos durante el siglo $\mathrm{xIX}$ - entre ganaderos e industriales. Teóricamente, aquéllos disponían de un mercado interior protegido, consumidor prioritario de la lana procedente de la cabaña nacional, y sólo exportaban a otros países europeos — donde debían someterse a la cotización internacional- el sobrante de la fibra no adquirida por las fábricas españolas. En la práctica, sin embargo, la protección nunca fue lo suficientemente efectiva ni para mantener un precio más alto de la materia textil -el mercado español, aunque con un cierto retraso, siguió la misma tendencia a la baja que el europeo- ni para impedir que, desde fechas tempranas, los fabricantes de hilados y tejidos de lana comenzaran a orientarse hacia el consumo de fibra extranjera: lana sajona en un principio, a la que se añadiría más tarde la estambrera o de peine.

Esta tensión, que en definitiva se reducía a la lucha entre dos tendencias proteccionistas, fluctuó de acuerdo con los vaivenes de una política arancelaria

"Parejo (en prensa). 
excesivamente compensatoria, pero fue común a todo el período estudiado $y$, además, se saldó con un balance claramente favorable a los industriales textillaneros, que en todo momento encontraron las suficientes facilidades para adquirir en el exterior una fibra que, por calidad o tipo, no podían comprar en España. En fin, el deterioro de las relaciones entre ambos grupos llegó a generar una importante fisura en la propia burguesía industrial catalana - evidentemente, los algodoneros estaban al margen del problema-, en su intento por crear un frente proteccionista común con los agricultores castellanos.

En efecto, la legislación arancelaria española fue progresivamente permisiva con la importación de lana en bruto al menos hasta 1891: en 1841 y 1849 se admitieron, respectivamente, la lana sajona y la estambrera, aunque imponiendo unos derechos lo suficientemente elevados como para limitar su introducción sólo a aquellas fábricas que comenzaban a trabajar el hilo de carda de calidad superior - pañería fina, de novedad-, o iniciaban las primeras pruebas con el estambre. En el primer caso, y según se expresaba desde la Junta de Aduanas y Aranceles en 1840, se trataba de facilitar a los fabricantes una materia prima de la que no disponían en España e, indirectamente, de procurar la reactivación de la producción interior de lanas:

... Muy penetrada se haya la Junta de la importancia de la grave necesidad de trabajar incesantemente en el sentido de que nuestras lanas ocupasen otra vez en el mundo fabril el puesto único y elevadísimo en el que se conservaron por tantos años. Debe recordar esta disposición de su ánimo para que no se extrañe la propuesta de admitir al comercio las lanas de Sajonia, conocidas como primas electorales [...] sin el empleo de estas lanas electorales no se pueden conseguir los paños delicadísimos que ostenta la industria extranjera. Nosotros distamos todavía de sus progresos, y como varias naciones fabricantes de paños, carecemos de tan preciosa materia. Ellas las reciben porque la necesitan y no la tienen. Iguales son las razones para que nosotros la recibamos, ya que por otra parte su consumo no perjudica a la producción nacional... ${ }^{43}$.

En cuanto al estambre, los industriales catalanes venían presionando, al menos desde mediados de la década de los cuarenta, para que la legislación contemplara la importación de este tipo de fibra, empleando parecido argumento que en el caso de la lana de carda de procedencia sajona:

4s Cit. por López. Martínez (1879), p. 29. 
... es absolutamente preciso para fomentar el desarrollo de esta preciosa industria, se permita la entrada, con un módico derecho, de las lanas que no poseemos, como son, la especial inglesa de hebra larga y fina y la superfina alemana estambrera, de que se hacen los estambres llamados merinos, y que es imposible elaborar con las actuales muestras de este nombre... ${ }^{46}$.

La continua presión de los fabricantes laneros —especialmente de los valle. sanos, quienes llegaron a declarar que con las lanas nacionales sólo podían llegar a fabricar paños de mediana calidad ${ }^{47}$ - determinó un nuevo descenso del gravamen a partir de 1852 , año en que comenzaron a reducirse los derechos de entrada de la lana de carda sajona (de 37,5 ptas. los $100 \mathrm{kgs}$. a 22,5 y, luego, a 16,5 para la fibra en sucio), tendencia confirmada en la reforma de 1862 ( 27 ptas/100 kgs. para la lana sajona lavada), en la que, además, se consideró la entrada de lana peinada (con un derecho de 60 ptas $/ 100 \mathrm{kgs}$.) y se limitó la imposición a que hasta entonces quedaba sujeta la importación de lana común (de 100 a 33 ptas.), extremos revisados nuevamente en $1863-65$ (34,8 pesetas para la lana peinada y 18 para la común) ${ }^{48}$.

En 1869, el llamado «arancel Figuerola» terminó por confirmar, frente a las pretensiones ganaderas, la orientación «industrialista» de la política comercial española respecto al abastecimiento de materias primas, considerado, además, como el elemento clave que permitiría alcanzar la modernización y expansión del sector textil, que, en última instancia, se esperaba promover con la nueva legislación aduanera:

... que la reforma arancelaria [escribía el propio Laureano Figuerola en 1870] ha sido beneficiosa para las industrias que se decían amenazadas, pues facilitando con la baja de los derechos una mayor importación de todos aquellos artículos que sirven de base o primera materia de las transformaciones que aquéllas realizan, es evidente que se les ha ofrecido mayor alimento, y que las rebajas de los derechos ha sido para ellas un medio de disminuir el costo de producción, haciendo más fácil la competencia con el producto extranjero ${ }^{49}$.

Frente a la división anterior, el nuevo texto sólo contemplaba la importa. ción de lana común (a la que se imponian unos derechos de 28 ptas $/ \mathrm{kgs}$.),

to Ibid., p. 31 .

47 Ibid., p. 30.

* Ibid., pp. 37 y ss. Según Figuerola, «en la revisión de 1862 se franqueó la puerta sin escrúpulo, con evidente ventaja para la industria...». Figuerola (1879), p. 107.

"Figuerola (1870), p. 535. 
englobando el resto en una única partida, señalada con un gravamen de $12,50 \mathrm{ptas} / \mathrm{kgs}$. La reforma de 1869 abrió las puertas a la masiva entrada de lana del exterior, no exclusivamente por el sensible descenso de los derechos arancelarios que determinó, sino más aún por su ambigua redacción, que, al no distinguir estados ni calidades de la fibra (lana sucia y lavada; lana de carda o de peine), acentuó todavía más el proceso de desplazamiento de las lanas en sucio por aquellas que previamente habían sido sometidas a las operaciones de lavaje y, de éstas, por las lanas peinadas y el estambre hilado. Como se observa en el cuadro 4, fue a finales de los años sesenta cuando se inició esta nueva distribución porcentual de las importaciones de fibra, que se mantendría aproximadamente hasta comienzos de la década finisecular, ya que a partir de ese momento el fuerte crecimiento estambrero impuso un nuevo ritmo de importación.

Fue entonces también cuando comenzó a consolidarse una infraestructura importadora que permanecería al menos durante el resto de la centuria, y que consistía fundamentalmente en recibir las lanas coloniales a través de Francia, donde eran lavadas previamente a su introducción en España. Para los industriales laneros -especialmente para los vallesanos-, calidad y precio, a los que se unían cada vez más las ventajas arancelarias, rentabilizaban una dependencia exterior en el abastecimiento de fibra, continuamente denunciada por los ganaderos españoles:

\section{CUADRO 4}

España. Importación de lana. Medias anuales (Distribución porcentual en equivalente lana lavada)

\begin{tabular}{|c|c|c|c|c|c|c|}
\hline & & $\begin{array}{l}\text { Lana } \\
\text { sucia }\end{array}$ & $\begin{array}{l}\text { Lana } \\
\text { lavada }\end{array}$ & $\begin{array}{c}\text { Lana } \\
\text { peinada }\end{array}$ & Estambre & Total \\
\hline $1851-1855$ & $\begin{array}{llll}\ldots & \ldots & \ldots\end{array}$ & 39,0 & 61,0 & & & 100 \\
\hline $1856-1860$ & $\begin{array}{llll}\ldots & \ldots & \ldots\end{array}$ & 28,7 & 71,3 & & & 100 \\
\hline $1861-1865$ & $\ldots \quad \ldots \quad \ldots$ & 10,0 & 79,5 & 10,5 & & 100 \\
\hline $1866-1870$ & $\begin{array}{llll}\ldots & \ldots & \ldots\end{array}$ & 11,4 & 59,4 & 28,1 & 1,1 & 100 \\
\hline 1871.1875 & $\begin{array}{lll}\ldots & \ldots & \ldots\end{array}$ & 11,2 & 67,0 & 18,8 & 2,0 & 100 \\
\hline $1876-1880$ & $\begin{array}{llll}\ldots & \ldots & \ldots\end{array}$ & 22,2 & 47,0 & 29,0 & 1,8 & 100 \\
\hline $1881-1885$ & $\begin{array}{llll}\ldots & \ldots & \ldots\end{array}$ & 8,0 & 64,0 & 23,5 & 4,5 & 100 \\
\hline $1886-1890$ & $\ldots \quad \ldots \quad \ldots$ & 4,4 & 65,3 & 24,8 & 5,5 & 100 \\
\hline 1891.1895 & $\begin{array}{llll}\ldots & \ldots & \ldots\end{array}$ & 2,8 & 36,5 & 55,2 & 5,5 & 100 \\
\hline $1896-1900$ & $\begin{array}{lll}\ldots & \ldots & \ldots \\
\ldots & \ldots & \ldots\end{array}$ & 0,7 & 18,7 & 77,8 & 2,8 & 100 \\
\hline
\end{tabular}

Fuente: ECEX. Elaboración propia. 
... favorecidos además con la baratura de los transportes [escribía un ganadero cacereño en relación con las fibras ultramarinas en 1876], sus lanas llegan a los puertos del Mediodía de Francia en rama o en las pieles, sufren allí las operaciones del lavado y estracción del cardillo que les perjudica, y aun pasando por esa mano intermedia que les impone el gravamen natural para su beneficio, vienen a ofrecerse en nuestros mercados naturales de Cataluña por unos precios que producirán la muerte inmediata de nuestra industria ganadera si a ello no se opone el único remedio que, en nuestro concepto, puede impedirlo: regularizar los derechos de introducción de esas lanas, elevándolos en la medida conveniente para no estorbar su concurrencia, proporcionando así un aumento considerable a los ingresos de aduanas, pero haciendo a la vez posible la existencia de nuestra ganadería y de una competencia que sea provechosa bajo todos aspectos... ${ }^{50}$.

En cualquier caso, el arancel de 1869 provocó en los fabricantes de hilados y tejidos de lana una situación cuando menos atípica: de un lado se encontraban muy a gusto con las posibilidades de importación de materia textil que les brindaba, pero al mismo tiempo se oponían frontalmente - sobre todo desde la reforma de 1877- a las disposiciones que regulaban la entrada de manufacturas. Esto último determinó que unieran sus esfuerzos con el resto de la burguesía catalana - mayoritariamente algodonera-, con la que, sin embargo, no llegaron a cerrar filas, debido precisamente a su postura en relación con la lana importada ${ }^{51}$.

La reforma arancelaria de 1877 introdujo por primera vez la doble columna de derechos en la política comercial española ${ }^{52}$, pero no modificó sustancialmente la política favorable a los intereses industriales que, en lo referente a la importación de materias primas, había confirmado el arancel Figuerola. Más aún, aunque atendiendo a las presiones ganaderas terminó por distinguir entre lanas sucias y lavadas, tanto la entrada en vigor de la segunda columna como una redacción que continuaba siendo confusa terminaron por compensar el teórico aumento del gravamen que la nueva clasificación contemplaba.

De tal forma, se conservaba un derecho de 28 ptas. para la lana común sucia, rebajándolo a 24 en el caso de las naciones convenidas - segunda colum. na-, mientras que a las partidas «lanas de las demás clases y la larga para

so GI (1876), p. 244.

s1 Esta fisura, detectada hace ya algún tiempo por Miquel Izard (1979), se agudizó a partir de 1875, una vez finalizada la Guerra Carlista. Sobre las relaciones entre la dirección del Fomento de la Producción Nacional y el Centro Industrial de Sabadell, véase FPN, Correspondencia, V, 23-II-1875.

${ }_{32}$ Serrano (1987), pp. 25.26. 
estambres» se le señalaban 12,5 y 7,6 ptas., respectivamente. Las lanas lavadas quedaron tarifadas con un derecho doble al de las sucias ${ }^{53}$.

La entrada en vigor de la segunda columna permitió mantener el mismo sistema de importación de lana, ya que a finales de 1877 se firmó con Francia un primer convenio por el que se le concedía la cláusula de «nación más favorecida" ${ }^{54}$. Este acucrdo, según lo estipulado en el nuevo arancel, permitiría que toda la fibra lavada que, sin tener la consideración de «común», entrase en España a través del país vecino lo hiciese con un derecho de 15,2 ptas/ 100 kgs., cantidad similar a la que los industriales importadores debían satisfacer hasta ese momento - 12,50 ptas. - y, por supuesto, mucho menor que la pretendida por los ganaderos españoles, repetidamente expuesta por su Asociación General ${ }^{55}$.

El papel intermediador francés se consolidó en 1881 con la creación del Banco de Sabadell, nacido con el doble objetivo, en palabras de Benaul, de dedicarse a las operaciones de banca y a la compraventa de lanas extranjeras ${ }^{56}$. La nueva institución financiera vallesana abrió sucursales en la capital bonaerense y estableció lavaderos en el sur de Francia, que incluso se dedicaban a preparar lanas que eran consumidas por las fábricas francesas y alemanas ${ }^{57}$.

El convenio hispano-francés de 1877 , firmado en principio por dos años, fue prorrogado hasta que en febrero de 1882 se alcanzó el definitivo acuerdo cntre ambas partes, que, al menos en lo que afectaba a la importación de lanas, mantuvo las disposiciones contempladas en el arancel todavía en vigor ${ }^{58}$. De ahí que sólo influyeran relativamente en el volumen de entrada de fibra el arancel de 1882 -que, teóricamente, imponía 56 y 48,6 ptas. para la primera y segunda co'umnas, respectivamente- $\mathrm{e}$ incluso la compensatoria ley de materias primas promulgada al año siguiente (una única columna con 12,24 y 33 ptas. para las lanas sucias, lavadas y peinadas) ${ }^{59}$, ya que, como ha quedado expuesto más arriba, aquella lana lavada procedente de Francia sólo estaba gravada con un derecho de 15,2 ptas $/ \mathrm{kgs}$. El cuadro 5 termina por aclarar la cuestión, al reflejar el abrumador porcentaje de fibra que a lo largo de todo el último tercio del siglo XIX procedía de suelo francés: tanto la lana de carda de calidad como la estambrera - lavada o peinada - y, en menor medida, el estambre, hilado preferentemente en las fábricas inglesas, sobre todo en la década finisecular.

${ }^{33} \mathrm{GI}, 10 . \mathrm{VII}-1877$, p. 225.

${ }^{34}$ Serrano (1987), pp. 40 y ss. Concretamente, el 8 de diciembre.

55 López Martínez (18;9), pp. 53 y ss.; GA, 14-IV-1878, pp. 3.9.

so Benaul (1981).

" GA, 16-I-1890, p. 237.

5* El texto del tratado de comercio con Francia, en DSCD, 5.IV-1882, apéndice 1, pp. 3-12.

sy Sobre el arancel de 1882 y la Ley de Primeras Materias, Serrano (1987), pp. 46.54. 


\section{CUADRO 5}

Distribución porcentual de las importaciones españolas de lana (por paises), $1870-1900$

1. LANA COMUN (sucia o lavada)

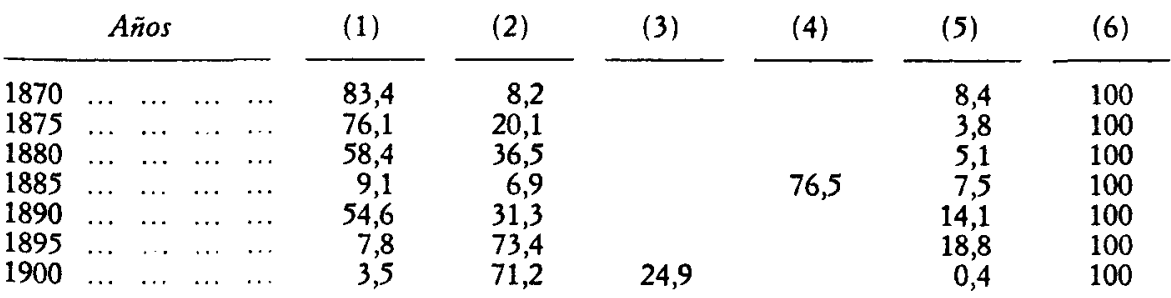

2. LANA SAJONA Y ESTAMBRERA (sucia y lavada)

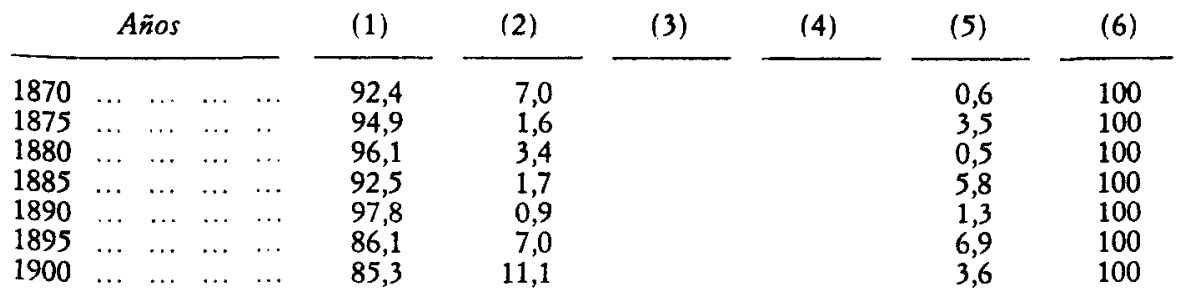

3. LANA PEINADA Y PREPARADA PARA ESTAMBRE

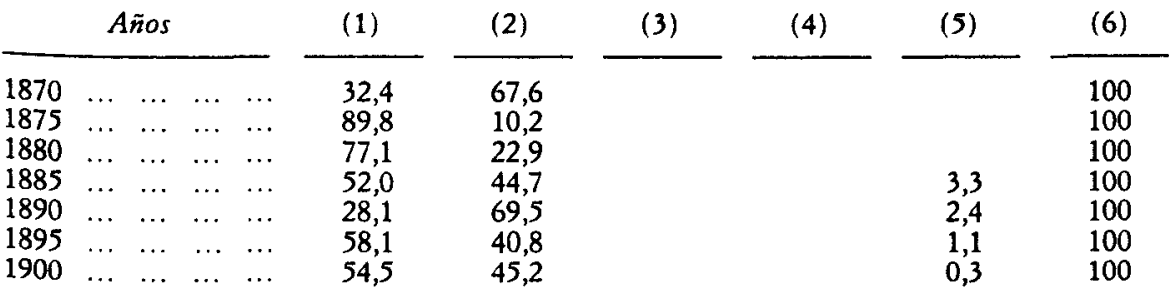

4. ESTAMBRE HILADO, BLANCO Y TENIIDO

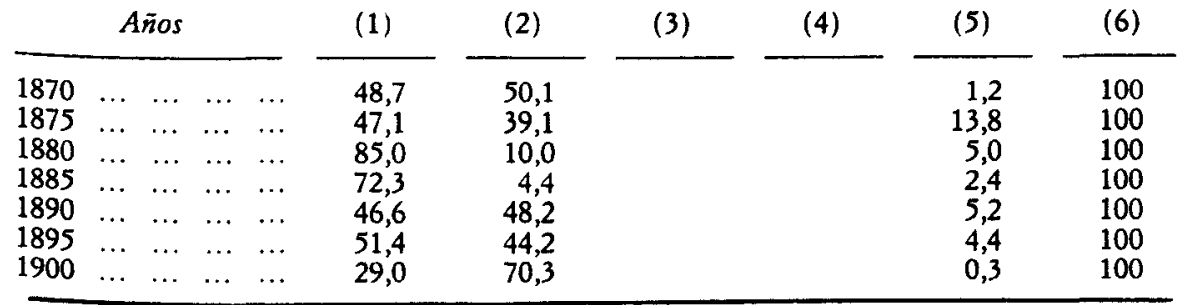

(1) Francia. (2) Inglaterra. (3) Bélgica. (4) Marruecos. (5) Resto de países. (6) Total. FuENTE: ECEX. Elaboración propia. 
En conjunto, la ley de materias primas de 1883 fue aceptada satisfactoriamente por los industriales laneros; aun cuando, como vimos más arriba, la rebaja en las lanas sajonas y estambreras les afectaba escasamente, sí les suponía un descenso considerable en los derechos satisfechos por aquella lana no procedente de Francia, debido sobre todo a la reducción del gravamen pagado por la fibra común sucia (de 24 a 28 ptas., según procediera de países con los que España tenía o no convenio, a 12 ptas $/ 100 \mathrm{kgs}$. como derecho general) ${ }^{60}$. Además, como quiera que se trataba del tipo de lana que la cabaña nacional estaba en condiciones de poder proporcionar a la industria lanera, no debe extrañar que arreciaran las protestas de los ganaderos ${ }^{61}$, mientras que en las Cortes la única oposición frontal al proyecto provino, una vez más, de Bosch y Labrús ${ }^{62}$.

En fin, aunque a finales de la década de los ochenta se produjeron algunas iniciativas para importar directamente desde Argentina la fibra, una vez lava$\mathrm{da}^{63}$, el papel reexportador de Francia se mantuvo durante los últimos años del siglo xix. La única modificación se produjo - y puede observarse tanto en el cuadro 4 como en el 5 - en el incremento de la lana peinada en el total importado, fenómeno relacionado con el crecimiento de la industria estambrera y con el nuevo arancel de 1891 , que elevaba considerablemente los derechos de entrada de materia prima textil ( 54 y 45 ptas/100 kgs. para la lana lavada en la primera y segunda columnas, y 66 y 55 ptas. para la peinada y cardada). Por este arancel -más en concreto, por su segunda columna- se reguló el nuevo tratado firmado con Francia en 1892, lo que también explica esta nueva orientación, al crecer porcentualmente mucho más el gravamen sobre la lana lavada que sobre aquella que se importaba, además, peinada y preparada para estambres ${ }^{64}$.

\section{a'd) El consumo aparente de lana en la segunda mitad del siglo XIX}

De acuerdo con lo expuesto en los apartados anteriores, un primer intento de estimación alternativa de consumo puede establecerse partiendo de las correcciones realizadas sobre el volumen de producción nacional de lana lavada y las cifras de importación y exportación de fibra. Como quiera que para estos dos últimos casos disponemos de datos anuales de una fiabilidad aceptable,

${ }^{\infty}$ FTN (1883), pp. 14-15.

${ }^{61}$ Algunas de estas protestas, en GA, 16-VIII-1882, p. 493.

:2 DSCD, 12-III-1883, p. 1403. Véanse, también, las sesiones del 3, 13 y 16-III-1883.

- Uno de los proyectos más ambiciosos fue el presentado por Lorenzo Pascual de Cortada, basado en la creación de la sociedad "Lavadero de lanas de la República Argentina". GPL (1889), pp. 106-138.

o* De 15,2 ptas/100 kgs. a 45 para la lana lavada, y de 33,2 a 55 ptas. para la peinada. Sobre el nuevo arancel, Serrano (1987), pp. 164 y ss., y Gwinner (1973), pp. 317.333. 
me he permitido confeccionar una tercera serie anual en la que, tomando como años-base aquellos que ofrecen información censal sobre el número de cabezas lanares, se presenta una teórica evolución de la producción interior de lana, reducida a equivalentes de lana lavada. Así ha quedado conformado el cuadro 6 , en el que aparece también una cuarta columna (producción + importaciones - exportaciones) donde queda reflejado el consumo aparente de lana realizado por las fábricas de hilados y tejidos españolas entre 1849 y 1900.

\section{CUADRO 6}

Producción y consumo de lana en España, 1849-1900

(En toneladas métricas)

\begin{tabular}{|c|c|c|c|c|}
\hline & (1) & (2) & (3) & (4) \\
\hline 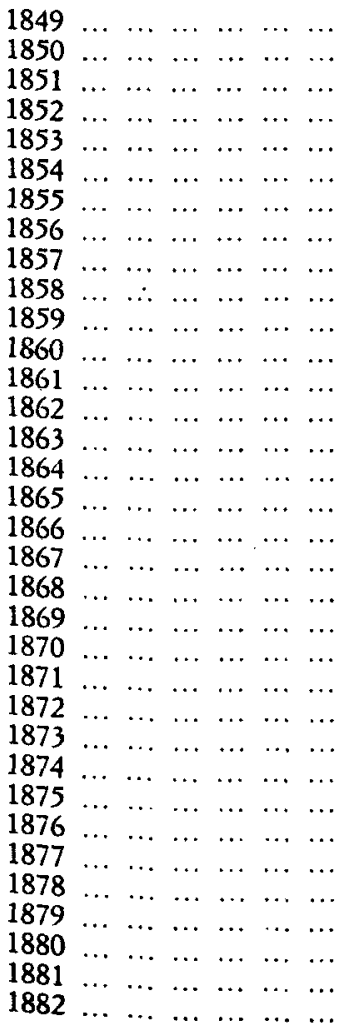 & $\begin{array}{l}15.014 \\
15.014 \\
15.014 \\
15.014 \\
15.014 \\
15.014 \\
15.014 \\
14.912 \\
14.811 \\
14.710 \\
14.609 \\
14.508 \\
14.406 \\
14.305 \\
14.204 \\
14.103 \\
14.002 \\
13.931 \\
13.859 \\
13.787 \\
13.716 \\
13.644 \\
13.572 \\
13.501 \\
13.428 \\
13.357 \\
13.285 \\
13.213 \\
13.142 \\
13.070 \\
12.998 \\
12.914 \\
12.791 \\
12.669\end{array}$ & $\begin{array}{r}2.452,8 \\
3.788,4 \\
2.973,1 \\
3.350,2 \\
2.042,9 \\
1.270,8 \\
2.584,6 \\
2.214,3 \\
2.603,9 \\
1.148,1 \\
1.502,3 \\
2.512,6 \\
1.557,5 \\
1.638,8 \\
1.409,3 \\
1.013,8 \\
800,6 \\
1.137,8 \\
1.464,3 \\
1.160,5 \\
1.126,4 \\
1.011,6 \\
1.907,2 \\
1.548,9 \\
1.096,4 \\
668,7 \\
1.441,2 \\
643,8 \\
1.401,1 \\
1.300,1 \\
1.328,9 \\
2.311,2 \\
1.315,6 \\
906,9\end{array}$ & $\begin{array}{r}35,3 \\
57,8 \\
27,8 \\
22,1 \\
24,7 \\
22,6 \\
36,1 \\
49,4 \\
48,5 \\
57,2 \\
76,1 \\
58,1 \\
126,1 \\
140,9 \\
284,9 \\
424,1 \\
157,3 \\
185,1 \\
275,6 \\
282,4 \\
326,5 \\
648,3 \\
871,5 \\
686,2 \\
1.074,2 \\
1.961,8 \\
1.532,6 \\
2.322,7 \\
1.112,3 \\
1.560,2 \\
743,4 \\
1.160,1 \\
1.821,9 \\
1.872,8\end{array}$ & $\begin{array}{l}12.596,5 \\
11.283,4 \\
12.068,7 \\
11.685,9 \\
12.995,8 \\
13.765,8 \\
12.465,5 \\
12.747,1 \\
12.255,6 \\
13.619,1 \\
13.182,8 \\
12.053,5 \\
12.974,6 \\
12.807,1 \\
13.079,6 \\
13.513,3 \\
13.358,7 \\
12.978,3 \\
12.670,3 \\
12.908,9 \\
12.916,1 \\
13.280,7 \\
12.536,3 \\
12.638,3 \\
13.405,8 \\
14.650,1 \\
13.376,4 \\
14.891,9 \\
12.853,2 \\
13.330,1 \\
12.412,5 \\
11.762,9 \\
13.297,3 \\
13.634,9\end{array}$ \\
\hline
\end{tabular}




\section{CUADRO 6 (Continuación)}

Producción y consumo de lana en España, 1849-1900

(En toneladas métricas)

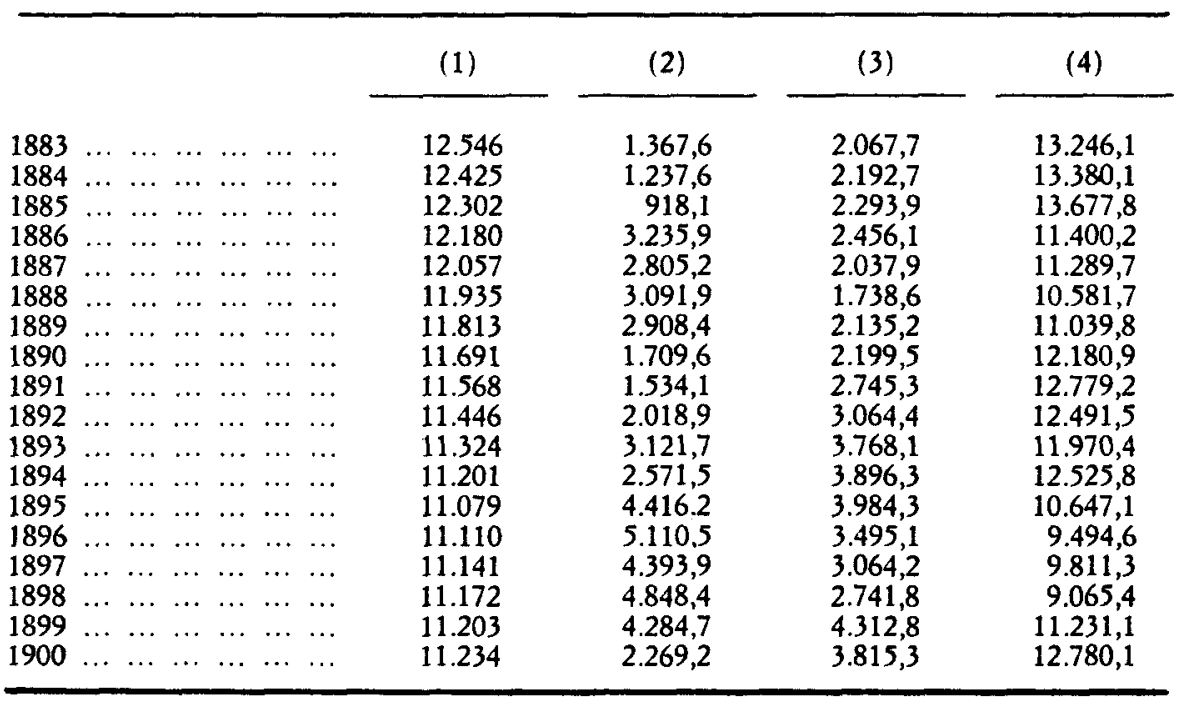

(1) Producción nacional de lana lavada.

(2) Exportaciones. Equivalentes en lana lavada (2).

(3) Importaciones. Equivalentes en lana lavada.

(4) Consumo aparente de lana $(1-2+3)$.

Fuente: Véase texto. ECEX. Elaboración propia.

¿Pueden aceptarse estas cifras de consumo como válidas para el período estudiado? Ciertamente, presentan una evolución distinta a la ofrecida en el panel 4 del cuadro 1 por Sánchez-Albornoz, Leandro Prados y Albert Carreras, quienes, considerando un índice 100 en el consumo de lana para 1860-65, estimaban para 1890-91 unos índices mucho más reducidos $(46,4,63,4$ y 55,7, respectivamente), mientras que, en el que nos ocupa, el descenso entre una y otra fecha es sólo de 4,4 puntos (95,6 por 100); de otro lado, la evolución anual parte de unos niveles elevados a mediados del xix, que crecen levemente hasta finales de los años setenta, para bajar a partir de esa fecha y de forma algo más acusada en el último quinquenio de la centuria.

Sin embargo, no podemos olvidar que el componente fundamental del consumo interior en el cuadro 6 sigue siendo una columna realizada a base de estimaciones que, a su vez, se sustentan sobre cálculos que frecuentemente pre- 
sentan amplios márgenes de error. Piénsese que, al menos hasta 1880 —cuando los datos acerca de la cabaña nacional son más fiables-, se trata del volumen máximo de aprovechamiento que podían realizar las fábricas laneras, pero no del que en realidad consumían, imposible de calcular con los datos disponibles. Por el contrario, en las décadas finales de siglo - años en que las cifras que poseemos sobre el volumen de la cabaña ovina son más precarias- aparece una nueva variable que vuelve a distorsionar las estimaciones: el creciente empleo de lana regenerada y rehilada, que, por supuesto, escapa a cualquier intento de contabilización.

Además, para todo el período, estamos todavía ante datos que siguen contrastando con la evolución del subsector, que creció especialmente a partir de los años sesenta-setenta, tanto en el número de husos y telares en funcionamiento como en la capacidad técnica de los mismos: desde el punto de vista de la productividad resulta difícil sostener las cifras de consumo de fibra ofrecidas por el cuadro 6 , ya que, manejando la información más fiable de que disponemos sobre utillaje empleado en el hilado - la aportada por las ECI de 1856 y 1900 -, resultaría que, a mediados del xIx, a cada huso corresponderían 120,4 kgs. de lana hilados anualmente, por sólo $37,7 \mathrm{kgs}$. para el último año del siglo, cantidades totalmente incompatibles con el incremento de la productividad operado en el subsector.

¿Existe alguna otra alternativa a la estimación del consumo de fibra basado en el volumen de la producción interior de lana? Hasta el momento, Albert Carreras es el único que, al no considerar representativos los resultados obtenidos por este método, ha aportado para la segunda mitad del siglo xIX una nueva evaluación, basada en la elaboración de los datos facilitados por las ECI, y en concreto por la Matrícula Industrial - número de husos y telares- de Sabadell y Tarrasa. El citado autor lleva a cabo sus cálculos a partir del establecimiento de cuotas constantes para un año intermedio - 1879-, con el fin de obviar las posibles variaciones a que podía estar sujeta la presión tributaria ${ }^{65}$. Naturalmente, Carreras ofrece así una visión muy distinta de la evolución del consumo de fibra realizado por el subsector lanero en el período citado, que ahora muestra un crecimiento prácticamente constante a partir de 1861 , acentuado incluso en el primer quinquenio de la década finisecular ${ }^{66}$. Una visión que, no obstante, ha sido recientemente discutida por Leandro Prados, para quien presenta un grave inconveniente: «la contribución de Cataluña en general, y de Sabadell y Tarrasa en particular, a la industria lanera española aumenta de manera significativa entre 1856 y 1900 . De este hecho se deduce que la utilización de la matrícula industrial de Sabadell y Tarrasa para repre-

\footnotetext{
${ }^{65}$ Carreras (1983 a), II, pp. 540 y ss.

of Ibid., pp. $570-571$ y 584 .
} 
sentar el conjunto de la industria nacional sesgaría al alza la serie de producto final, y exageraría su crecimiento durante la segunda mitad del siglo XIX» ${ }^{67}$.

El propio Prados de la Escosura considera que una nueva opción estimativa podría derivarse de la aplicación del método de cuotas constantes a la matrícula industrial de toda España, por lo que apunta la posibilidad de construir dos índices alternativos para la industria lanera en la segunda mitad del XIX: «uno a partir de la oferta de lana, y otro de la matrícula industrial en cuotas constantes de Sabadell y Tarrasa, que representarían, respectivamente, los lí. mites inferior y superior de su crecimiento» ${ }^{68}$.

Por mi parte, y aunque comparto con Prados la necesidad de construir un índice alternativo que incluya todo el conjunto español, considero que las estimaciones basadas en la producción interior de lana no ofrecen el nivel mínimo que el expresado autor les otorga, sino uno más o menos adecuado a la evolución real del consumo, pero en todo caso alejado de unos cálculos que se pretendan aproximados, especialmente hasta finales de los años setenta. De ahí que también acepte como base de una nueva estimación el número de husos en funcionamiento, aunque, frente a Carreras, no empleo el método de cuotas constantes para elaborarlo, sino que me baso en la capacidad productiva de los husos en activo a lo largo del período considerado.

Parto, para ello, de la apreciación realizada por los ingenieros al servicio del Ministerio de Hacienda, quienes, a finales del siglo xix, establecieron en $46,72 \mathrm{kgs} / \mathrm{año}$ la producción de un huso de carda, y en $24,96 \mathrm{kgs} /$ año la de uno de estambre ${ }^{69}$. A partir de estas cifras he reconstruido el volumen de lana hilada en Sabadell-Tarrasa - únicas localidades sobre las que se disponen series anuales ininterrumpidas ${ }^{70}-\mathrm{y}$, empleando las matrículas industriales de toda España, he ampliado el volumen resultante al total nacional, teniendo en cuenta la diferente participación productiva de los husos dedicados a lana de peine y a lana cardada, así como, en última instancia, la que todavía representaban aquellos que seguían estando movidos a mano ${ }^{71}$. El resultado, para la segunda mitad del Ochocientos, se recoge en el cuadro 7.

oi Prados (1988), pp. 156-157.

of Ibid., p. 157 .

๑) Memorias (1900); GM, 21-IV-1900.

${ }^{70}$ Carreras (1983 a), II, pp. 570-571; Benaul (1981).

"El método de elaboración que he seguido ha sido el siguiente: para los años en que disponemos datos de toda España, he calculado el porcentaje de husos representado por Sabadell/Tarrasa (porcentaje sobre total nacional de husos mecánicos matriculados) para $1856(22,2$ por 100$), 1863(37,5$ por 100$), 1879(44,9$ por 100$), 1890(42,6$ por 100$)$ y 1900 (31,2 por 100). A continuación, para poder reconstruir series anuales, he enlazado los porcentajes anteriores, estableciendo la relación a partir de los husos de carda en funcionamiento en el Vallés $(100$ por 100 hasta 1880 , 90 por 100 entre $1881-90$ y 65 por 100 para la década finisecular), a la que luego he sumado los husos de estambre. Por último, procedo de forma parecida con los husos manuales, a los que estimo una producción huso/ año de $11,6 \mathrm{kgs}$. 


\section{CUADRO 7}

\section{Producción de bilados de lana en España, 1851-1900 \\ (En toneladas métricas)}

\begin{tabular}{|c|c|c|c|c|c|c|c|c|c|c|c|c|c|c|c|c|c|}
\hline $\begin{array}{l}1851 \\
1852 \\
1853 \\
1854 \\
1855\end{array}$ & $\begin{array}{l}\cdots \\
\cdots \\
\cdots \\
\cdots \\
\cdots\end{array}$ & $\begin{array}{l}\cdots \\
\cdots \\
\cdots \\
\ldots \\
\cdots\end{array}$ & $\begin{array}{l}\cdots \\
\cdots \\
\cdots \\
\cdots \\
\cdots\end{array}$ & $\begin{array}{l}\cdots \\
\cdots \\
\cdots \\
\cdots \\
\cdots\end{array}$ & $\begin{array}{l}\cdots \\
\cdots \\
\cdots \\
\cdots \\
\cdots\end{array}$ & $\begin{array}{l}\cdots \\
\cdots \\
\cdots \\
\cdots \\
\cdots\end{array}$ & $\begin{array}{l}\cdots \\
\cdots \\
\cdots \\
\cdots \\
\cdots\end{array}$ & $\begin{array}{l}1.606,1 \\
3.625,0 \\
4.369,1 \\
5.833,5 \\
3.032,8\end{array}$ & $\begin{array}{l}1876 \\
1877 \\
1878 \\
1879 \\
1880\end{array}$ & $\begin{array}{l}\ldots \\
\cdots \\
\cdots \\
\cdots \\
\cdots\end{array}$ & $\begin{array}{l}\cdots \\
\ldots \\
\ldots \\
\ldots \\
\ldots\end{array}$ & $\begin{array}{l}\ldots \\
\cdots \\
\ldots \\
\cdots \\
\ldots\end{array}$ & $\begin{array}{l}\cdots \\
\cdots \\
\cdots \\
\cdots \\
\cdots\end{array}$ & $\begin{array}{l}\cdots \\
\cdots \\
\cdots \\
\cdots \\
\cdots\end{array}$ & $\begin{array}{l}\cdots \\
\cdots \\
\cdots \\
\cdots \\
\cdots\end{array}$ & $\begin{array}{l}\cdots \\
\cdots \\
\cdots \\
\cdots \\
\cdots\end{array}$ & $\begin{array}{l}11.382,3 \\
11.719,3 \\
11.545,5 \\
11.457,5 \\
11.433,3\end{array}$ \\
\hline $\begin{array}{l}1856 \\
1857 \\
1858 \\
1859 \\
1860\end{array}$ & $\begin{array}{l}\ldots \\
\cdots\end{array}$ & $\begin{array}{l}\ldots \\
\ldots \\
\ldots \\
\ldots \\
\cdots\end{array}$ & $\begin{array}{l}\ldots \\
\cdots \\
\cdots \\
\cdots \\
\cdots\end{array}$ & $\begin{array}{l}\ldots \\
\cdots \\
\cdots \\
\cdots \\
\cdots\end{array}$ & $\begin{array}{l}\ldots \\
\cdots \\
\cdots \\
\cdots \\
\cdots\end{array}$ & $\begin{array}{l}\ldots \\
\ldots \\
\cdots \\
\cdots \\
\ldots\end{array}$ & $\begin{array}{l}\ldots \\
\ldots \\
\cdots \\
\cdots \\
\cdots\end{array}$ & $\begin{array}{l}5.089 \\
3.801 \\
8.194 \\
7.502 \\
8.172\end{array}$ & $\begin{array}{l}1881 \\
1882 \\
1883 \\
1884 \\
1885\end{array}$ & $\begin{array}{l}\ldots \\
\cdots \\
\cdots \\
\cdots \\
\cdots\end{array}$ & $\begin{array}{l}\ldots \\
\ldots \\
\ldots \\
\cdots \\
\cdots\end{array}$ & $\begin{array}{l}\ldots \\
\cdots \\
\cdots \\
\cdots \\
\cdots\end{array}$ & $\begin{array}{l}\ldots \\
\cdots \\
\cdots \\
\cdots \\
\cdots\end{array}$ & $\begin{array}{l}\ldots \\
\cdots \\
\cdots \\
\cdots \\
\cdots\end{array}$ & $\begin{array}{l}\cdots \\
\cdots \\
\cdots \\
\cdots \\
\cdots\end{array}$ & $\begin{array}{l}\cdots \\
\cdots \\
\cdots \\
\cdots \\
\cdots\end{array}$ & $\begin{array}{l}11.082,7 \\
11.608,0 \\
12.107,3 \\
13.067,2 \\
12.855,1\end{array}$ \\
\hline $\begin{array}{l}1861 \\
1862 \\
1863 \\
1864 \\
1865\end{array}$ & $\begin{array}{l}\ldots \\
\cdots \\
\cdots \\
\cdots \\
\cdots\end{array}$ & $\begin{array}{l}\ldots \\
\cdots \\
\ldots \\
\cdots \\
\cdots\end{array}$ & $\begin{array}{l}\cdots \\
\cdots \\
\cdots \\
\cdots \\
\cdots\end{array}$ & $\begin{array}{l}\cdots \\
\cdots \\
\cdots \\
\cdots \\
\cdots\end{array}$ & $\begin{array}{l}\cdots \\
\cdots \\
\cdots \\
\cdots \\
\cdots\end{array}$ & $\begin{array}{l}\ldots \\
\cdots \\
\cdots \\
\cdots \\
\cdots\end{array}$ & $\begin{array}{l}\ldots \\
\ldots \\
\cdots \\
\cdots \\
\cdots\end{array}$ & $\begin{array}{l}7.292,6 \\
5.226,5 \\
8.631,8 \\
8.723,2 \\
7.939,2\end{array}$ & $\begin{array}{l}1886 \\
1887 \\
1888 \\
1889 \\
1890\end{array}$ & $\begin{array}{l}\ldots \\
\ldots \\
\cdots \\
\cdots \\
\cdots\end{array}$ & $\begin{array}{l}\ldots \\
\ldots \\
\ldots \\
\ldots \\
\ldots\end{array}$ & $\begin{array}{l}\ldots \\
\ldots \\
\ldots \\
\cdots \\
\cdots\end{array}$ & $\begin{array}{l}\cdots \\
\cdots \\
\cdots \\
\cdots \\
\cdots\end{array}$ & $\begin{array}{l}\ldots \\
\ldots \\
\cdots \\
\cdots \\
\cdots\end{array}$ & $\begin{array}{l}\ldots \\
\cdots \\
\cdots \\
\cdots \\
\cdots\end{array}$ & $\begin{array}{l}\cdots \\
\cdots \\
\cdots \\
\cdots \\
\cdots\end{array}$ & $\begin{array}{l}12.977,9 \\
12.050,6 \\
11.484,5 \\
10.544,6 \\
10.021,5\end{array}$ \\
\hline $\begin{array}{l}1866 \\
1867 \\
1868 \\
1869 \\
1870\end{array}$ & $\begin{array}{l}\cdots \\
\cdots \\
\cdots \\
\cdots\end{array}$ & $\begin{array}{l}\ldots \\
\ldots \\
\ldots \\
\ldots \\
\cdots\end{array}$ & $\begin{array}{l}\cdots \\
\cdots \\
\cdots \\
\cdots \\
\cdots\end{array}$ & $\begin{array}{l}\ldots \\
\cdots \\
\cdots \\
\cdots \\
\cdots\end{array}$ & $\begin{array}{l}\ldots \\
\ldots \\
\cdots \\
\cdots \\
\cdots\end{array}$ & $\begin{array}{l}\cdots \\
\cdots \\
\cdots \\
\cdots \\
\cdots\end{array}$ & $\begin{array}{l}\ldots \\
\cdots \\
\cdots \\
\cdots \\
\cdots\end{array}$ & $\begin{array}{l}8.994,1 \\
8.400,2 \\
8.675,0 \\
8.074,2 \\
8.373,1\end{array}$ & $\begin{array}{l}1891 \\
1892 \\
1893 \\
1894 \\
1895\end{array}$ & $\begin{array}{l}\ldots \\
\ldots \\
\ldots \\
\ldots \\
\ldots\end{array}$ & $\begin{array}{l}\ldots \\
\ldots \\
\ldots\end{array}$ & $\begin{array}{l}\ldots \\
\ldots \\
\ldots \\
\ldots \\
\cdots\end{array}$ & $\begin{array}{l}\ldots \\
\cdots \\
\cdots \\
\cdots \\
\cdots\end{array}$ & $\begin{array}{l}\cdots \\
\cdots \\
\cdots \\
\cdots \\
\cdots\end{array}$ & $\begin{array}{l}\ldots \\
\cdots \\
\cdots \\
\cdots \\
\cdots\end{array}$ & $\begin{array}{l}\ldots \\
\cdots \\
\cdots \\
\cdots \\
\cdots\end{array}$ & $\begin{array}{r}9.098,7 \\
9.434,7 \\
11.217,8 \\
12.686,7 \\
12.516,4\end{array}$ \\
\hline $\begin{array}{l}1871 \\
1872 \\
1873 \\
1874 \\
1875\end{array}$ & $\ldots$ & $\begin{array}{l}\ldots \\
\ldots \\
\ldots\end{array}$ & $\begin{array}{l}\ldots \\
\cdots \\
\cdots\end{array}$ & $\begin{array}{l}\cdots \\
\cdots \\
\cdots \\
\cdots \\
\cdots\end{array}$ & $\begin{array}{l}\ldots \\
\cdots \\
\cdots \\
\cdots \\
\ldots\end{array}$ & $\begin{array}{l}\ldots \\
\cdots \\
\cdots \\
\cdots \\
\cdots\end{array}$ & $\begin{array}{l}\cdots \\
\cdots \\
\cdots \\
\cdots \\
\cdots\end{array}$ & $\begin{array}{r}9.897,1 \\
10.994,0 \\
9.966,9 \\
9.930,7 \\
10.019,2\end{array}$ & $\begin{array}{l}1896 \\
1897 \\
1898 \\
1899 \\
1900\end{array}$ & $\begin{array}{l}\ldots \\
\ldots \\
\ldots \\
\ldots \\
\ldots\end{array}$ & $\begin{array}{l}\ldots \\
\cdots \\
\ldots \\
\ldots \\
\ldots\end{array}$ & $\begin{array}{l}\ldots \\
\ldots \\
\ldots \\
\ldots \\
\ldots\end{array}$ & $\begin{array}{l}\cdots \\
\cdots \\
\cdots \\
\cdots \\
\cdots\end{array}$ & $\begin{array}{l}\ldots \\
\cdots \\
\cdots \\
\ldots \\
\ldots\end{array}$ & $\begin{array}{l}\cdots \\
\cdots \\
\cdots \\
\cdots \\
\ldots\end{array}$ & $\begin{array}{l}\cdots \\
\cdots \\
\cdots \\
\cdots \\
\cdots\end{array}$ & $\begin{array}{l}12.141,7 \\
11.512,6 \\
10.735,7 \\
10.188,7 \\
10.619,1\end{array}$ \\
\hline
\end{tabular}

FUENTES: ECI (1856, 1863, 1879, 1890 y 1900); Carreras (1983 a). Elaboración propia.

Esta nueva estimación, que al basarse en datos sobre utillaje contempla también la lana regenerada que era consumida por las fábricas de hilados, no está, sin embargo, exenta de inconvenientes. En primer lugar, aunque son aceptables los datos que ofrecen las matrículas de Contribución Industrial de la zona vallesana, los del total nacional están calculados partiendo de una información menos fiable - las ECI-, en la que no debe estar ausente una cierta infravaloración de las máquinas de hilar en funcionamiento - debido a fraudes, desgravaciones fiscales, etc. ${ }^{22}$ - Asimismo, se trata de una producción por huso calculada sobre un tipo de maquinaria existente en 1899 , y a la que se

${ }^{72}$ Sobre el tema de las desgravaciones fiscales a la industria lanera y al textil en general, véanse Carreras (1983 a), II, pp. 540-541; Carreras (1983 b). 
le adjudican unos niveles de consumo de fibra difícilmente alcanzables por los núcleos textiles no catalanes, sujetos a serias deficiencias energéticas que impedían su utilización a lo largo de todo el año.

Con todo, pienso que la valoración final de la alternativa que ofrezco puede ser aceptable: mucho más que la basada en el volumen de la oferta interior y exterior de lana, con la que, no obstante, presenta una cierta concordancia a partir de los años ochenta - relacionada, evidentemente, con el mayor empleo de la fibra nacional y el fuerte incremento de las importaciones-. Una estimación que, ahora sí, presenta un panorama del subsector lanero muy alejado del ofrecido inicialmente por Sánchez-Albornoz y Prados de la Escosura, donde el crecimiento del consumo de fibra realizado por las fábricas españolas contrasta con la estrepitosa caída que ambos autores señalaban para las décadas finales de siglo. Una estimación, en fin, que puede resultar apropiada para elaborar, a partir de ella, unos nuevos índices de producción y consumo de tejidos de lana que abarquen toda la segunda parte del siglo xIX.

\section{SIGLAS UTILIZADAS}

CEA: Comisión Especial Arancelaria.

DSCD: Diario de Sesiones del Congreso de los Diputados.

ECEX: Estadisticas del Comercio Exterior de España, Dirección General de Aduanas, 1849-1900, Madrid.

ECI: Estadisticas administrativas de la Contribución Industrial y de Comercio, 1856, 1863, 1879,1890 y 1900 , Madrid.

EEF: España Económica y Financiera, 1893-1899, Madrid.

EP: El Eco de la Producción, 1880-1885, Barcelona.

FPN: Fomento de la Producción Nacional.

FTN: Fomento del Trabajo Nacional.

GA: La Gaceta Agricola del Ministerio de Fomenlo, 1877-1894, Madrid.

GEHR: Grupo de Estudios de Historia Rural.

GI: La Gaceta Industrial, 1856-1891, Madrid.

GM: La Gaceta de Madrid, 1849-1900, Madrid.

GPL: La Gaceta de la Producción Lanera, 1885.1892, Tarrasa.

ILE: La Industria Lanera Española, 1880-1882, Tarrasa.

RA: La reforma arancelaria y los tratados de comercio. Información escrita de la Comisión nombrada por RD de 10-X-1889, VI vols., 1890, Madrid. 


\section{BIBLIOGRAFIA}

Anes, G.; Artola, M.; Fontana, J., y Tedde, P. (eds.) (1982): La economía española al final del Antiguo Régimen, 4 vols., Alianza, Madrid.

- ; Rojo, L. A., y TEDDE, P. (eds.) (1983): Historia económica y pensamiento social. Ensayos bomenaje a Diego Mateo del Peral, Alianza, Madrid.

ARAGó, D. (1893): Tratado del ganado lanar y cabría, su cría, mejora, razas, productos, entermedades, etc., Madrid.

Arán, S. (1958): Ganado lanar y cabrio. Su explotación económica, Madrid.

Benaul, J. M. (1981): «Notes sobre la industrialització a Sabadell (1780-1898)», Arrahona, pp. $55-78$.

BERG, M. (1987): La era de las manufacturas, 1700-1820. Una nueva bistoria de la revolución industrial británica, Crítica, Barcelona.

Carreras, A. (1983 a): La producció industrial espanyola $i$ italiana des mitian segle XIX fins a l'actualitat, tesis doctoral inédita, 2 vols., Universidad Autónoma de Barcelona.

- (1983 b): «El nuevo aprovechamiento de la energía hidráulica en Cataluña, 1840-1920. Una aproximación a su estudio", RevisTa DE Historia Económica, 2, pp. 31-64.

Estapé, F. (ed.) (1973): Textos olvidados, Instituto de Estudios Fiscales, Madrid.

Figuerola, L. (1870): «Memoria relativa al estado general de la Hacienda», en F. Estapé (ed.), pp. $501-558$.

- (1879): La reforma arancelaria de 1869, Madrid.

Gallego, D. (1986): La producción agraria de Alava, Navarra y La Rioja desde mediados del siglo XIX a 1935, tesis doctoral, Universidad Complutense, Madrid.

Gaminde, B. F. (1827): Memoria sobre el estado actual de las lanas merinas españolas y su cotejo con las extranieras. Causas de la decadencia de las primeras y remedio para mejorarlas, Madrid.

García SAnz, A. (1978): «La agonía de la Mesta y el hundimiento de las exportaciones laneras: un capítulo de la crisis económica del Antiguo Régimen en Españan. Agricultura y Sociedad, 6, pp. 283-356.

Garrabou, R.; Barcifila, C., y Jiménez Blanco, J. I. (eds.) (1986): Historia Agraria de la España Contemporánea. 3. El fin de la agricultura tradicional (1900-1960), Crítica, Barcelona.

Grupo de Estudios de Historia Rural (1978-79): «Contribución al análisis histórico de la ganadería española», Agricultura y Sociedad, 8, pp. 129-182; 10, pp. 105-169.

Gwinner, A. (1973): «La política comercial española en los últimos decenios», en F. Estapé (ed.), pp. 253-334.

Información sobre las consecuencias que ba producido la supresión del derecho diferencial de bandera y sobre las valoraciones y clasificación de los tejidos de lana. Sesiones de la Comisión Especial Arancelaria (1883), tomo III, Madrid.

IzARD, M. (1979): Manufactureros, industriales y revolucionarios, Crítica, Barcelona.

Jiménez Blanco, J. I. (1984): La producción agraria en Andalucía Oriental, 1874-1914, tesis doctoral, Universidad Complutense, Madrid.

- (1986): «Introducción», en R. Garrabou, C. Barciela y J. I. Jiménez Blanco (eds.), pp. 9-141.

Junta Consultiva Agronómica (1892): La ganadería en España. Avance sobre la riqueza pecuaria en 1891. Formado por la..., conforme a las memorias reglamentarias que en el cilado año ban redactado los ingenieros del servicio agronómico, 5 vols., Madrid.

Laguna, E. (1986): Historia del merino, Ministerio de Agricultura, Pesca y Alimentación, Madrid.

LÓPEz MARTínez, M. (1879): La producción lanera y los aranceles, Madrid.

LlopIs, E. (1982): «Las explotaciones transhumantes en el siglo xVIII y primer tercio del xix: la cabaña del Monasterio de Guadalupe, 1709.1835», en G. Anes, M. Artola, J. Fontana y P. Tedde (eds.), tomo I, pp. 1-102.

Martón, J. (1908): Industria y comercio de las lanas, Madrid. 
Memorias sobre la industria fabril redactadas por los ingenieros al servicio de la investigación de la Hacienda Pública (1900), Madrid.

NADAL, J. (1987): "La industria fabril española en 1900. Una aproximación», en J. Nadal, A. Carreras y C. Sudrià (eds.), pp. 23-61.

- ; Carreras, A., y Sudria, C. (eds.) (1987): La economía española en el siglo XX. Una perspectiva bistórica, Ariel, Barcelona.

- y Maluquer, J. (1985): Catalunya, la fábrica d'Espanya. Un siglo de industria'ización cataiana, 1833-1936, Ayuntamiento de Barcelona.

PARejo, A. (en prensa): La industria lanera española en la segunda milad del siglo XIX.

Prados de la Escosura, L. (1982): Comercio exterior y crecimiento económico en España, 1826-1913: tendencias a largo plazo, Banco de España, Madrid.

- (1983): «Producción y consumo de tejidos en España, 1800-1913. Primeros resultados», en G. Anes, L. A. Rojo y P. Tedde (eds.), pp. 455.474.

- (1988): De imperio a nación. Crecimiento y atraso económico en España (1780-1930), Alianza, Madrid.

Ronquillo, J. A. (1857): Diccionario de materia mercantil, industrial y agricola, tomo IV, Barcelona.

SÁnchez-Albornoz, N. (1981): «El consumo de textiles en España», Hacienda Púb'ica Española, 69, pp. 229-235.

Serrano, J. M. (1987): El viraje proteccionista en la Restauración. La política comercial española, 1875-1895, Siglo XXI, Madrid.

Tortella, G. (1981): «La economía española, 1830-1900», en M. Tuñón de Lara (ed.), vol. VIII, pp. 11-168.

TuÑón DE LARA, M. (ed.) (1981): Historia de España, 11 vols., Labor, Barcelona.

Zapata, B. A. (1820): Noticia del origen y establecimiento incrcible de las lanas finas de España en el extranjero, por culpa nuestra de no baber impedido mejor la extracción de nuestro ganado lanar, Madrid.

Zapata, S. (1986): Lo producción agraria en Extremadura y Andalucia Occidental, 1875. 1835, tesis doctoral, Universidad Complutense, Madrid. 